\title{
UNDER-BODY FORCED-AIR WARMING BLANKET VERSUS RESISTIVE HEATING BLANKET FOR PREVENTION OF HYPOTHERMIA DURING SPINAL SURGERY: A RANDOMIZED PROSPECTIVE STUDY
}

\author{
Shariffuddin $I^{1}$, Hasan $\mathrm{MS}^{1}$, Chong $\mathrm{TH}^{1}$, Kwan $\mathrm{MK}^{2}$, Chan $\mathrm{YK}^{1}$ \\ 1 Department of Anesthesiology, Faculty of Medicine, University of Malaya, Kuala Lumpur \\ 2 Departments of Orthopaedics, Faculty of Medicine, University of Malaya, Kuala Lumpur
}

\author{
Correspondence: \\ Dr. Ina Ismiarti Shariffuddin \\ Department of Anesthesiology, Faculty of Medicine \\ University of Malaya, 50603 Kuala Lumpur, Malaysia \\ Email: inashariffuddin@gmail.com \\ Tel: +60379492052 \\ Fax: +60379556705
}

\begin{abstract}
Background:

Prevention of hypothermia in patients undergoing major posterior approach spinal surgery can be difficult, as a large body surface is exposed to the cold environment of the operating theatre. We compared the efficacy of a new under-body forced-air warming blanket with that of a resistive heating blanket in preventing hypothermia.

\section{Methods:}

Sixty patients undergoing major posterior approach spinal surgery lasting for more than 2 hours were randomly assigned to warming with a full under-body forced-air warming blanket or three segments of resistive heating blankets, both set at $42^{\circ} \mathrm{C}$. The ambient temperature was kept near $20^{\circ} \mathrm{C}$. Nasopharyngeal, rectal and axillary temperatures were measured at regular intervals. Changes in core temperature (average of nasopharyngeal and rectal) over time were compared by the independent t-test.
\end{abstract}

\section{Results:}

The characteristics of the patients were comparable. The baseline core temperature was $36.36 \pm 0.38^{\circ} \mathrm{C}$ in the forced-air group and $36.27 \pm 0.46^{\circ} \mathrm{C}$ in the resistive heating group. During the first hour, the core temperature decreased similarly from baseline in both groups. From 100 minutes after induction until the end of the surgery, core temperature rose in both groups. At the end of surgery, the core temperature was increased by 0.08 $\pm 0.09^{\circ} \mathrm{C}$ from baseline in the forced-air group but decreased by $0.40 \pm 0.04^{\circ} \mathrm{C}$ from baseline in the resistive heating group. The difference in the change of the core temperature, at the end of the surgery, between the two groups is statistically significant $(P<0.05)$.

\section{Conclusion:}

We demonstrated that the new under-body forced-air warming blanket is superior to the resistive heating blanket in preventing hypothermia in patients undergoing major posterior approach spinal surgery.

Keywords: forced-air warming, resistive heating, blanket, hypothermia, spinal surgery

\section{Introduction}

Perioperative hypothermia is associated with morbidity in general surgical patients (1). Adverse consequences of even mild hypothermia include morbid myocardial events (2), coagulopathy (3), increased transfusion requirements (4), surgical wound infection and prolonged hospitalisation $(5,6)$, prolonged recovery (7) and thermal discomfort (8). 
Perioperative hypothermia is common and results from anaesthetic-induced inhibition of thermoregulatory control, core-to-peripheral heat redistribution and the cold operating environment. Thus, preventive measures to reduce perioperative hypothermia with active warming devices have become standard practice unless hypothermia is otherwise indicated. The most common perioperative warming system is convective warming with forced-air currents or air streaming over the patient $(9,10)$. Forcedair warming systems have consistently been shown to maintain normothermia, even during major operations (11). However, in major posterior approach spinal surgery, thermoregulation of patients can be challenging. A large area of the anterior body surface of these patients is exposed to the cold environment of the operating room, which can lead to major heat loss. Forced-air warming blankets have been used to warm only the upper posterior part of the patients' body or the lower limbs. Resistive heating systems provide alternative types of warming blankets as they can selectively heat up different body segments simultaneously. Resistive heating systems have comparable efficacy to forced-air warming systems in maintaining core temperature during major open abdominal surgery (12), total hip replacement surgery (13) and in heat transfer and core re-warming rates (14). Unfortunately, in posterior approach spinal surgery, the resistive heating system can warm only the upper posterior part of the body and the lower limbs. The anterior body surface area is still exposed to the cold operating room environment. Thus, there is a need for a warming blanket that can provide heat to this part of the body.

Recently, a new full-body forced-air warming blanket was developed, which is placed under the body of the patient undergoing spinal operation in the prone position on a Jackson table. This blanket covers the anterior body surface area and the lower limbs. It transfers heat to the available anterior skin surface, which is normally exposed to the cold environment.
Therefore, in this prospective, randomised study, our aim was to compare the efficacy of this new under-body forcedair warming blanket with that of resistive heating blanket in preventing hypothermia in patients undergoing major posterior approach spinal surgery.

\section{Methods}

With approval from the Ethics Committee of University Malaya Medical Centre and with written, informed consent, we studied 60 patients undergoing elective spinal surgery. All patients were American Society of Anesthesiologists (ASA) classification I or II, aged 12-80 years old, undergoing spinal surgery on a Jackson table in the prone position with operation duration of a minimum of two hours. Patients with preoperative pyrexia, evidence of current infection, thyroid disease, recent head injury with disturbance of autonomic functions or use of vasoactive drugs, were excluded from the study.

\section{Participating patients were randomly assigned to:}

1. Forced-air warming group: full under-body forcedair warming blanket that covers almost the whole ventral surface of the patient's body; face, anterior trunk, both upper limbs and lower limb placed underneath the body (Figure 1 ) with controller set to high temperature $\left(42^{\circ} \mathrm{C}\right.$ ) (Bair Hugger Arizant Healthcare Inc., USA) or

2. Resistive heating group: three pieces of carbon-fibre resistive heating blanket; one large upper body blanket that covers upper back and both upper limbs and two separate 'lower limbs' blankets that wrap up the lower limbs (Figure 2). The temperature of these blankets was set to $42^{\circ} \mathrm{C}$ (Thermamed SmartCare OP system).

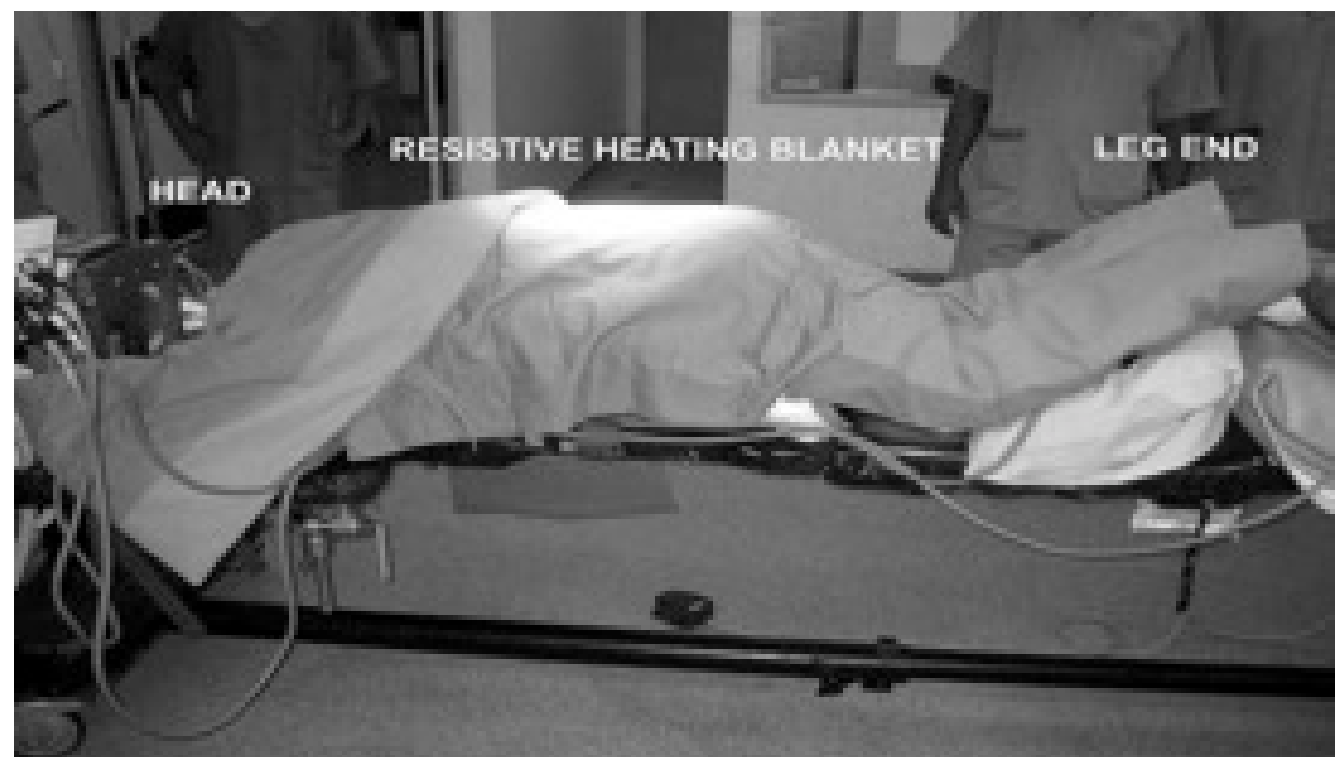

Figure 1: Picture showing the application of resistive heating blanket on patient during spinal surgery. 


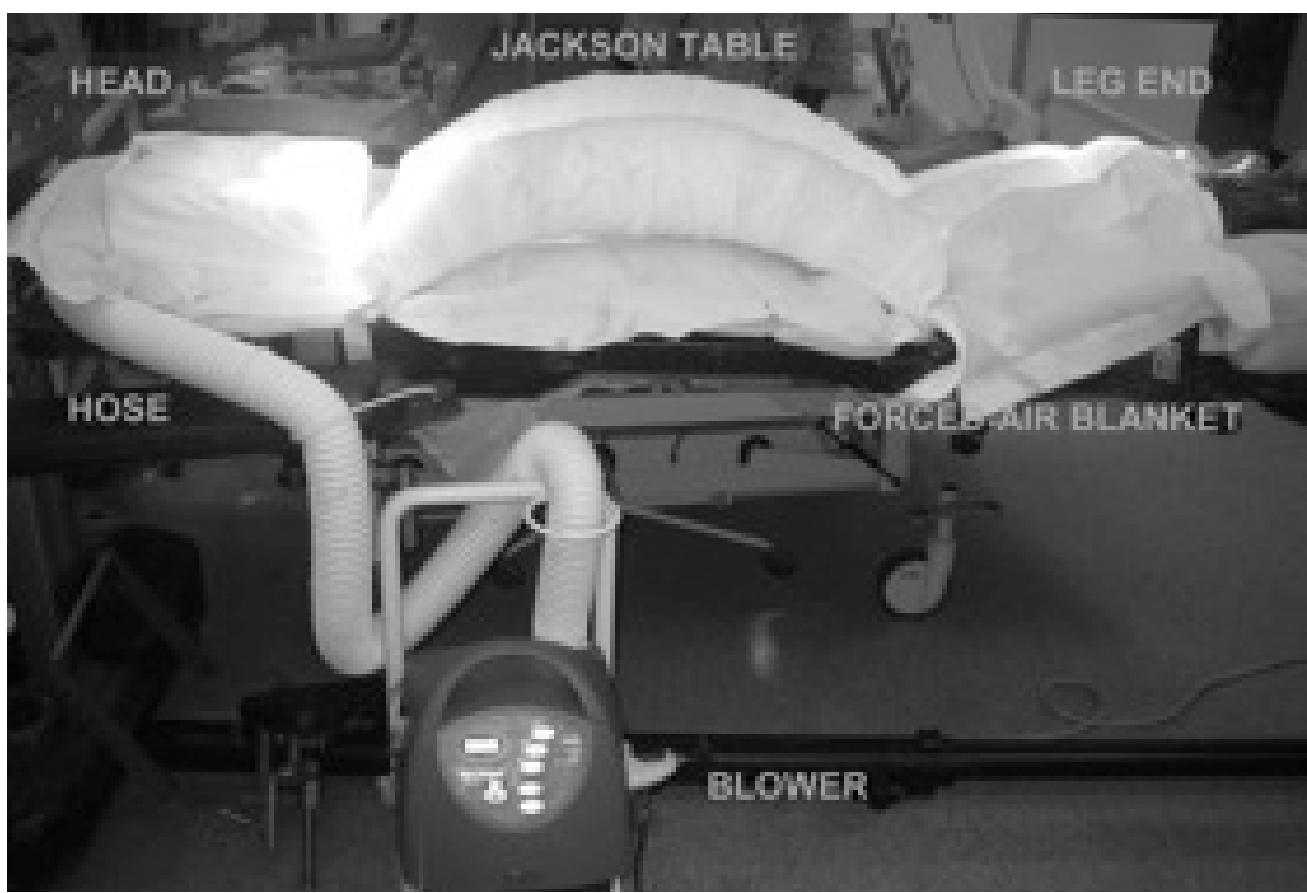

Figure 2: Picture showing the application of forced-air warming blanket on Jackson table during spinal surgery.

Randomisation was based on computer-generated codes sealed in numbered opaque envelopes and opened upon arrival of the patients in the operating room.

A thin layered cotton wool was used to wrap around the four limbs of all patients as soon as they arrived at the reception area. General anaesthesia was induced with fentanyl $1-2 \mu \mathrm{g} / \mathrm{kg}$ and propofol $2 \mathrm{mg} / \mathrm{kg}$, followed by atracurium $0.5 \mathrm{mg} / \mathrm{kg}$ or rocuronium $0.6-0.9 \mathrm{mg} / \mathrm{kg}$ to facilitate tracheal intubation, and was then maintained with sevoflurane $/ \mathrm{O}_{2} /$ air. All patients were mechanically ventilated to maintain end tidal $\mathrm{CO}_{2}$ with partial pressure between 33 - $36 \mathrm{mmHg}$.

A nasopharyngeal temperature probe was then inserted into the nostril with a marking of $5 \mathrm{~cm}$ at the patient's nose. A rectal temperature probe was inserted into the rectum with the surface marking at $8 \mathrm{~cm}$. A skin temperature probe was placed beneath one of the axilla of the patient with both arms in a diver's position. All temperatures were measured with thermocouples, with measurements starting at induction and continued throughout the surgery at 20-min intervals. Ambient temperature was measured with a thermocouple positioned at the level of the patient, well away from any heat-producing equipment. Skin temperature was measured at the axilla. Core temperature was measured at the nasopharynx and the rectum and was presented as an average value of two readings at any one time. Both core and skin temperatures were measured as a function of intraoperative time, with induction of general anaesthesia as time lapse of zero.

The operating room had controlled laminar air flow with room temperature set at $20^{\circ} \mathrm{C}$ and relative humidity of about $40 \%$. All intravenous fluids were warmed in a fluid warming device (HOTLINE Level 1 set at $41^{\circ} \mathrm{C}$ ). Patients were administered fluid according to this regimemaintenance of fluid with crystalloids at $7 \mathrm{ml} / \mathrm{kg} / \mathrm{h}$ and replacement of blood loss with colloid at ratio of 1:1. The transfusion trigger was a haemoglobin level of less than $8 \mathrm{~g} / \mathrm{dl}$.

Demographic, morphometric and clinical characteristics of participants and duration of surgery were recorded. Blood pressure, heart rate, oxygen saturation and end tidal carbon dioxide were recorded at 20-min intervals.

To detect a clinically significant difference equal to $0.3^{\circ} \mathrm{C}$ in final mean core temperature, we prospectively calculated that 30 patients were required in each group, assuming a standard deviation of $0.4^{\circ} \mathrm{C}(\alpha=0.05 ; \beta=0.2)$ (12).

The distribution of data was evaluated with the KolmogorovSmirnov test. All intraoperative measurements were averaged over time at each time point among patients in each treatment group. Differences among groups were compared using the independent t-test for variables. $P$ value $\leq 0.05$ was considered statistically significant. Continuous variables were presented as mean \pm standard deviation unless otherwise indicated.

\section{Results}

The characteristics and clinical details of patients in each group are shown in Table 1. No significant difference was found between groups. No evidence of thermal injury was observed related to any of the warming devices. 
Table 1: Patient characteristics

Forced-air warming blanket

Resistive heating blanket

Age (years)

$35 \pm 17$

$8 / 22$

22

Body mass index $(\mathrm{kg} / \mathrm{m} 2)$

Operation duration (min)

Mean Blood Pressure $(\mathrm{mmHg})$

Heart Rate (/min)

Oxygen saturation (\%)

End tidal $\mathrm{CO}_{2}(\mathrm{mmHg})$
$231 \pm 75$

72

78

99

35

$44 \pm 18$

$7 / 23$

57.6

23

$226.67 \pm 87$

75

72

99

34

* Characteristics and clinical details of patients warmed with either forced-air warming blanket or resistive heating blanket during spinal operation. Values are mean or mean \pm SD.

The baseline core temperatures in both groups were similar and did not significantly differ- $36.36 \pm 0.38^{\circ} \mathrm{C}$ for forced-air group and $36.27 \pm 0.46^{\circ} \mathrm{C}$ for resistive heating group. Patients in both groups showed a decrease in core temperature post-induction of anaesthesia. In the first hour, in the forced-air group, the core temperature decreased by $0.41^{\circ} \mathrm{C}$ from the baseline, while in resistive heating group the temperature dropped by $0.59^{\circ} \mathrm{C}$ from the baseline. This difference was not statistically significant $(P<0.05)$.

Core temperature increased at 100 minute post-induction until the end of the surgery in both groups. At the end of surgery, the core temperature in the forced-air group had increased by $0.08^{\circ} \mathrm{C}$ from the baseline, whereas, in the resistive heating group, the core temperature had decreased by $0.40^{\circ} \mathrm{C}$ from baseline $(P<0.05)$. (Figure 3 )

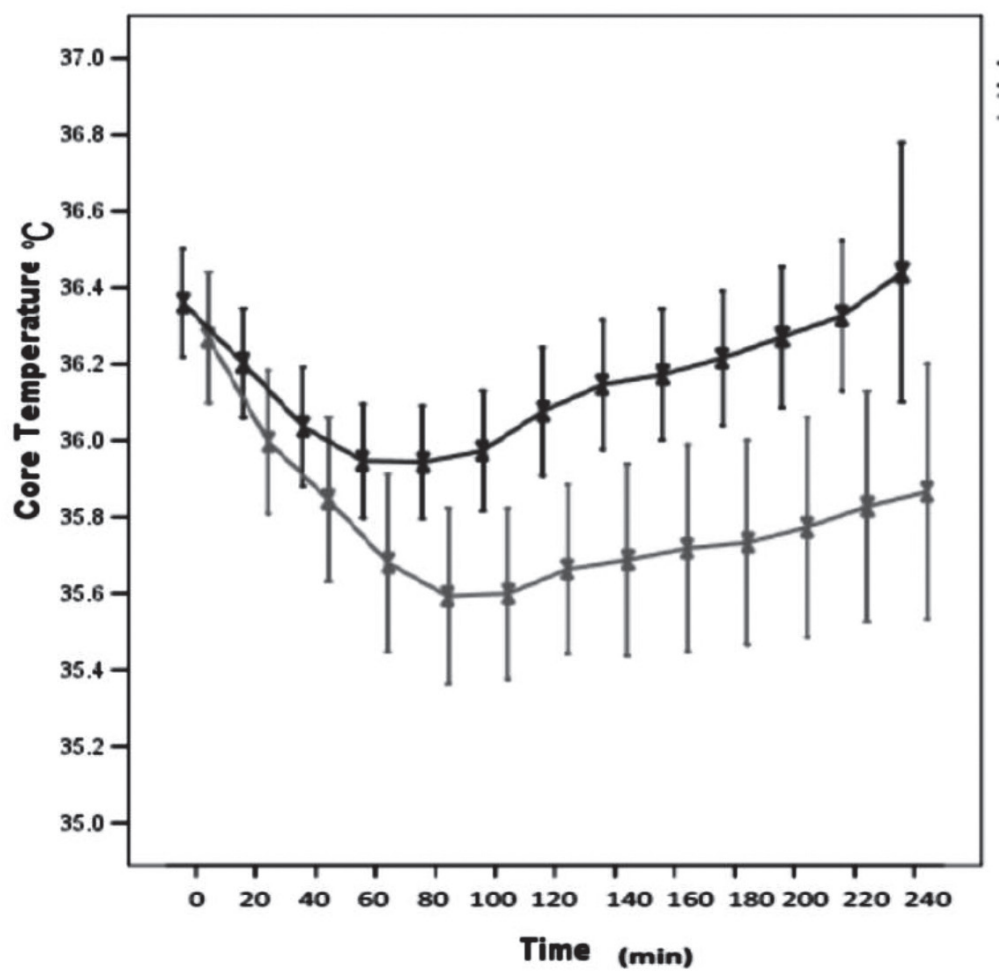

Type of device

I Forced air warming blanket

I Resistive heating blanket

Figure 3: Core temperature in patients warmed with forced-air warming blanket or resistive heating device during spinal surgery at different time points. Values are mean \pm confidence interval $95 \%$. 


\section{Discussion}

The forced-air blanket uses a warming system that depends on blower strength, air temperature and surface area covered to provide heat. The temperature of the blanket is controlled by a computer, which can be set between $32-42^{\circ} \mathrm{C}$. The disposable blanket is designed to cover the ventral body area of patients on the spinal surgery bed. It is soft and radiolucent, thus accommodating intraoperative imaging.

The resistive heating blanket (Thermamed SmartCare OP system) is a non-disposable blanket with semi-conductive carbon fibre and low-voltage direct current to provide heat. Its heating ability is controlled by a computer that sets the temperature between $37-42^{\circ} \mathrm{C}$. This blanket can independently warm several fields simultaneously. The blanket is made of semi-conductive carbon fibre and is therefore not radiolucent.

A thin layered cotton wool was used to wrap around the four limbs of all patients as soon as they arrived at the reception area in order to reduce the initial heat redistribution post-induction. The other reason for doing this is to avoid thermal injury due to direct contact of heat source, as a significant rise in temperature will be directly transferred to the patient with minimal dissipation. Burns have been reported with all types of heating blankets and are related to direct thermal injury (15) or due to device malfunction and inappropriate operation.

We have demonstrated that the efficacy of the full underbody forced-air warming blanket is superior over that of the resistive heating blanket in preventing hypothermia during major spinal operations lasting more than 2 hour. The superior efficacy of the forced-air blanket is probably due to the fact that it covered almost the entire ventral surface of the patients' body, whereas with the resistive blanket most of the anterior surface of patients' body was exposed directly to the cold ambient operation theatre temperature throughout surgery. The efficacy of active clinical warming devices is proportional to the available skin surface (16) and the design of the blanket (17).

A possible limitation of this study is that we did not analyse the blood loss at the end of surgery. However, we do not think our results are affected by this as we had a standardised regime to administer fluid for maintenance and replacement of any fluid and blood loss. In addition, all fluids administered to patients were warmed up to the point of entry into patients with fluid warming devices. Other studies also did not take into account the blood loss in their patients $(18,19)$.

Our results are inconsistent with those of several previous studies that showed comparable efficacy of forced-air warming, and resistive heating blankets in maintaining normothermia during open abdominal surgery (13) and laparoscopic cholecystectomy (18). Negishi et al (12) studied only eight patients in each treatment group undergoing open abdominal surgery with a forced-air warming blanket used to cover both lower limbs and resistive heating blanket used to cover one arm, chest and both legs. Matsuzaki et al (18) also studied eight patients in each group of patients undergoing laparoscopic cholecystectomy, with a forced-air warming blanket covering the upper body in the first group and a resistive heating blanket covering arms, chest and both legs in the second group. Thus, in these studies a larger surface was covered by resistive heating blankets than in our study.

We used the average of nasopharyngeal and rectal temperature as a measurement of core temperature. In other studies $(13,18)$, tympanic membrane temperature was used as core temperature. We decided to use the nasopharyngeal temperature as it has been shown to correlate well with the temperature of the thalamus, which is the site for thermoregulation. Rectal temperature was also measured, as it was shown to measure core temperature accurately and precisely (20). Therefore, by deriving core temperature from the average of these two measurements, it will best reflect core temperature of the patient. In addition, inserting an aural temperature probe into the tympanic membrane might damage the tympanic membrane, especially if it is inserted after general anaesthesia (21).

In this study, we showed that the full under-body forcedair warming blanket is able to keep the core temperature above the baseline to the end of surgery, whereas the core temperature at the end of surgery with the resistive heating blanket fell below baseline. As forced-air blankets are disposable, they can be more costly than resistive heating blankets. However, due to their efficacy and the importance of preventing hypothermia intra-operatively, we recommend that the full under-body forced-air warming blanket should be used in spinal operations.

\section{Conclusion}

This prospective and randomised study demonstrated the greater efficacy of the newly developed full under-body forced-air warming blanket over that of resistive heating blankets in preventing hypothermia in patients undergoing major posterior approach spinal surgery. Our study showed a blanket that covered a larger ventral body surface area was better in preventing intra-operative hypothermia than a blanket that covered a smaller surface area. Thus, in future, various designs of warming blanket should be developed to cater for different types of surgery.

\section{Acknowledgement}

The authors of this paper would like to thank the Spine Team from the Department of Orthopaedics, University of Malaya, Kuala Lumpur for their cooperation in this study. It was supported by Peruntukan Penyelidikan Jangka Pendek, PPP Grant University of Malaya P0031/2008C.

\section{References}

1. Sessler DI. Perioperative hypothermia. N Engl J Med 1997; 336:1730-7. 
2. Frank SM, Fleisher LA, Breslow MJ, Higgins MS, Olson KF, Kelly $\mathrm{S}$, et al. Perioperative maintenance of normothermia reduces the incidence of morbid cardiac events: A randomized clinical trial. JAMA 1997; 277:1127-34.

3. Winkler M, Akc.a O, Birkenberg B, Hetz H, Scheck T, Arkilic CF, et al. Aggressive warming reduces blood loss during hip arthroplasty. Anesth Analg 2000; 91:978-84.

4. Schmied H, Kurz A, Sessler DI, Kozek S, Reiter A. Mild intraoperative hypothermia increases blood loss and transfusion requirements during total hip arthroplasty. Lancet 1996; 347:289-92.

5. Seamon MJ, Wobb J. Gaughan JP, Kulp H, Kamel I, Dempsey DT. The effects of intraoperative hypothermia on surgical site infection: an analysis of 524 trauma laparotomies. Ann Surg 2012; 255:78995.

6. Kurz A, Sessler DI, Lenhardt RA. Study of wound infections and temperature group: Perioperative normothermia to reduce the incidence of surgicalwound infection and shorten hospitalization. $N$ Engl J Med 1996; 334:1209-15.

7. Lenhardt R, Marker E, Goll V, Tschernich H, Kurz A, Sessler DI, et al. Mild intraoperative hypothermia prolongs postanesthetic recovery. Anesthesiology 1997; 87:1318-23.

8. Kurz A, Sessler DI, Narzt E, Bekar A, Lenhardt $\mathrm{R}$, Huemer G. Postoperative hemodynamic and thermoregulatory consequences of intraoperative core hypothermia. J Clin Anesth 1995; 7: 359-66.

9. Kurz A, Kurz M, Poeschl G, Faryniak B, Redl G, Hackl B. Forced-air warming maintains intraoperative normothermia better than circulating-water mattresses. Anesth Analg 1993; 77:89-95.

10. Borms SF, Engelen SL, Himpe DG, Suy MR, Theunissen WJ. Bair hugger forced-air warming maintains normothermia more effectively than thermo-lite insulation. J Clin Anesth 1994; 6:303-7.

11. Lamb FJ, Rogers R. Forced-air warming maintains normothermia during orthotopic liver transplantation. Anaesthesia 1995; 50:745.

12. Negishi C, Kenji Hasegawa, Shihoko Mukai, Fumitoshi Nakagawa, Makoto Ozaki, Daniel I. Sessler. Resistive-
Heating and Forced-Air Warming Are Comparably Effective. Anesth Analg 2003; 96:1683-7.

13. Fanelli A, Giorgio Danelli, Daniela Ghisi, Andrea Ortu, Elisa Moschini, Guido Fanelli. The Efficacy of a Resistive Heating Under-Patient Blanket versus a Forced-Air Warming System: A Randomized Controlled Trial. Anesth Analg 2009; 108:199 -201.

14. Oliver Kimberger, Christine Held, Karin Stadelmann, Nikolaus Mayer, Corinne Hunkeler, Sessler DI. Resistive Polymer versus Forced-Air Warming: Comparable Heat Transfer and Core Rewarming Rates in Volunteers. Anesth Analg 2008; 107:1621-6.

15. Siddik-Sayyid SM, Saasouh WA, Mallat CE, Aouad MT. Thermal burn following combined use of forced air and fluid warming devices. Anaesthesia 2010; 65:654-5.

16. Sessler DI, Moayeri A. Skin-surface warming: heat flux and central temperature. Anesthesiology 1990; 73:218-24.

17. Anselm B, Henning B, Thorsten P, Wolfgang Z, Michael JM, Michael Q. What Determines the Efficacy of Forced-Air Warming Systems? A Manikin Evaluation with Upper Body Blankets. Anesth Analg 2009; 108:192-8.

18. Matsuzaki Y, Matsukawa T, Ohki K, Yamamoto Y, Nakamura M, Oshibuchi T. Warming by resistive heating maintains perioperative normothermia as well as forced air heating. Br J Anaesth 2003; 90:689-91.

19. Ng Siew-fong, Cheng-Sim Oo, Khiam-Hong Loh, PohYan Lim, Yiong-Huak Chan, and Biauw-Chi Ong. A Comparative Study of Three Warming Interventions to Determine the Most Effective in Maintaining Perioperative Normothermia. Anesth Analg 2003; 96:171-6.

20. Cattaneo, Christine G, Frank, Steven M, Hesel, Todd W. The Accuracy and Precision of Body Temperature Monitoring Methods during Regional and General Anesthesia. Anesth Analg 2000; 90:938-45.

21. Sessler DI. Temperature Monitoring and Perioperative Thermorehulation. Anesthesiology 2008; 109:318-38. 